Corrections to Met. Trans., 1973, Vol. 4

Thermodynamic Study of Liquid Cu-Mg Alloys by Vapor Pressure Measurements by S. P. Garg, Y. J. Bhatt, and C. V. Sundaram, pp. 283-89.

\title{
Page 284
}

Delete " $\delta$-" in the following places:

Table I, heading of last column

Table I, footnote

Lines 2, 4, and 7 following Equation [3]

\section{Page 285}

Line 3 following Equation [5b]:

Change $\log v_{\mathrm{Mg}}^{\circ}$ to $\log \gamma_{\mathrm{Mg}}^{\circ}$ 